\title{
The Effect Of Job Enrichment Schemes On Selected Construction Workers In Nigeria
}

Omotayo Olugbenga Aina

Department Of Building, Obafemi

Awolowo University, Ile-Ife, Nigeria

tayoaina@yahoo.com,

mcube@oauife.edu.ng
Alao Taiwo Omoniyi

(Research assistant, data gathering)

Department Of Building, Obafemi Awolowo

University, Ile-Ife, Nigeria
DOI 10.5592/otmcj.2014.1.3 Research paper

\section{Keywords}

Job Enrichment Schemes,

Analytical Hierarchical Process (AHP), Eigenvectors, Factor analysis, Effect of job enrichment, Performance of job enrichment
THERE IS A NEED TO ASCERTAIN THE EFFECT OF JOB ENRICHMENT SCHEMES ON WORKERS IN CONSTRUCTION INDUSTRY IN NIGERIA IN ORDER TO JUSTIFY ITS CONTINUOUS USE AS TOOLS FOR MOTIVATION. This study was designed to determine the relative performance of job enrichment schemes used by selected construction firms in Lagos, Nigeria and the effects of the schemes on the workers in these firms. The study was conducted with data from questionnaire retrieved from forty two project sites. The project managers and craftsmen on these sites were required to evaluate the performance of the job enrichment schemes they had used previously and the effect of those schemes on the workers. Ranking of the Analytical Hierarchical Process (AHP) vectors used for performance evaluation revealed that high performing job enrichment schemes were increased decision making ability, total quality management and training programmes. Factor analysis was further used to extract the following factors as the major effects of the job enrichment schemes on the construction workers; core job enrichment effects, workers self actualization effects, peer surveillance effects, workers dissatisfaction effects, workers behavioural effects and positive time effects. The ascertained effects justify continuous use of job enrichment schemes. 


\section{INTRODUCTION}

The survival and growth of a corporate organization depend to a large extent on the productivity of its workforce. Similarly, the wealth of a nation as well as socio-economic wellbeing of its people depend on the effectiveness and efficiency of its various sub components (Akinyele, 2007). Productivity is therefore of great importance to the individual worker, the organization, the national economy at large and therefore also important to the upliftment of the welfare of the citizen and reduction of mass poverty in the polity (Yesufu, 2000, Akinyele 2005). Productivity of the Nigerian worker has been adjudged lower than that of counterparts in the western world for decades. (Yesufu, 2000, Thingan 2005) Part of the efforts of the Nigerian government to improve productivity led to formation of national productivity centre in 1987. According to World Bank Report (2009), labour productivity in Nigeria is persistently low, labour productivity recorded an average growth rate of $1.2 \%$ from 2000-2008, this is below the $1.9 \%$ recorded in sub Saharan African countries (World Bank, 2009).

The Nigerian construction industry is not only an integral part of the economy, but also an influential part because of its contribution to the economy. Because the industry has remained largely non mechanized, but rely on large number of manual workers, it is also bogged down with the low productivity picture painted above (Wahab, 1984, Akindele, 2003).

A major method construction organizations employ to improve their workers productivity is the use of incentive schemes. Results of researches on the use of these schemes indicated they have induced increased productivity in workers in different proportions, (Aina, 2000; Fagbenle, 2003; Wahab, 1984; Ameh 2013). While these studies have been instructive, they have however, concentrated on either financial or non-financial incentives. Rarely are there studies on other members of the incentive family such as job enrichment/enhancement schemes

Job enrichment is a way to motivate workers by giving them opportunity to use a range of their abilities, this is done by giving them more responsibilities and varieties in their job. The purpose of job enrichment is to reverse the negative effects of repetitive tasks requiring autonomy, and having effects such as boredom, lack of flexibility and employees dissatisfaction. An enriched job will contain (a) a range of tasks and challenges of varying toughness (b) a complete unit of work and (c) feedback, encouragement and communication mechanisms. (Leach and Wall, 2004).

The earliest efforts on job enrichment was by Herzberg and later by Hackman and Oldham who designed a job characteristics model. Kotila (2001) reported that the model assumed that if five core job characteristics are present (skill variety, task identify, task significance, autonomy, feedback). Three psychological states critical to motivation will be produced in the worker, namely; meaningfulness of work, responsibilities for work outcomes and knowledge of results. Then there would be five positive job outcomes, namely; internal work motivation, job satisfaction, growth satisfaction low absenteeism and high quality performance. In a job enrichment programme conducted by Ohio state university (Mione, 2006) there were three groups of advantages recorded after five years of the programme. The three groups of advantages were (a) renewal consisting of reduction of boredom, making new contacts, thinking about new career options and change in view point (b) exploration, made up of the following: trying new skills, developing new relationships, testing management and administrative skills and (c) specialization, also consisting; re-education, indepth exploration using special skills and meeting a need that were underserved. These multifaceted advantages suggest that job enrichment has potentials for increasing workers productivity in general, perhaps also in the construction industry.

Earliest consideration of job enrichment in construction management literature witnessed low patronage and rejection by researchers. For example Borcherding and Oglesby, (1974) believed that satisfaction in construction work is inherent in the work itself and therefore, efforts to improve job satisfaction and productivity lie in well planned, smooth work flow rather than in job enrichment as advocated by organizational behaviourists for industrial sector jobs.

Similarly, Hazeltine (1976) also believed that effective motivation of construction workers will be best achieved by developing satisfactions inherent in the construction work itself. He further maintained that job enrichment programmes used in industrial work are not applicable to construction and that managers should capitalize on the existing motivation potentials of the construction work. However, as time progressed and the construction industry opened up to innovations, Maloney (1997) saw evidence of the use of job enrichment tools in the construction industry, and saw the similarities between job enrichment and self managing work teams in construction. But concluded then that enriched jobs were still largely limited to small construction firms and most times specialty contractors. In further acceptance of job enrichment Ruthankoon and Ogunlana (2003) prescribed job enrichment as a tool for increasing job satisfaction and performance. Doloi (2007) also recommended job enrichment schemes for addressing long term needs of construction workers.

Against the background of the two foregoing and opposing thoughts of on the one side; the usefulness of job enrichment in general management as espoused by Mione, (2006), Kotila, (s2001) and others and on the other 
side; the irrelevance of job enrichment in construction setting supported by Oglesby, ( 1974), Hazeltine, ( 1976) and others. It is necessary to understand the features of the job enrichment schemes being used in Nigeria construction industry. To ascertain whether it has effects on corporate goals by fostering it or it is just a wild goose chase.

To this send, this research was designed to determine the relative performance of the job enrichment schemes used by selected construction firms in Nigeria and the effect of the enrichment schemes on the workers in these firms.

\section{Job Enrichment Schemes}

Job enrichment means that additional motivators are added to the job so that it is more rewarding. The purpose of job enrichment is to relieve the boredom of the workers which flows from excessive specialization in mass production industries so that the job itself may be a source of self satisfaction. Job enrichment allows workers participation because they offer freedom and scope to them to use their judgment (Aswathappa, 2005).

According to Akrani (2011) job enrichment embraces some distinct features for effectiveness namely (a) the nature of the jobs are such that require higher-level knowledge, skills and responsibilities (b) the objective of an enriched job is such that the job is more lively and challenging, thus becoming a source of motivation to the staff (c) the enriched job is packaged to give positive results, because the workers are given opportunities to use their initiative and innovate while working and (d) an enriched job encourages self discipline, it reduces external direction and control.

There are numerous job enrichment schemes used in general management and industrial settings. But in this study, we are limited to eight types commonly used in construction settings in the study area. They are; task rotation, total quality management, work rest cycle/break, combined task, increased decision making opportunity for workers, training programmes, self managed gangs and workers participation in site meetings.

\section{Research Methodology}

This study was conducted with primary data obtained through a sample survey conducted with questionnaire and interviews. The explorative nature of the study necessitated the use of questionnaire. Questionnaires from forty two project managers and one hundred and ten craftsmen from ongoing construction projects in Lagos, Nigeria were retrieved and used for this study. The questionnaire was constructed according to the objectives of the study. The first section was designed to determine the relative performance of the job enrichment schemes the project managers have used before this survey. The analytical hierarchical process (AHP) was adopted to analyze the relative judgments among the job enrichment schemes because of its strength in eliciting accurate qualitative data. The forty two projects managers acted as the panel for the AHP evaluation.

The second objective of the study was to determine the effect of job enrichment schemes on construction workers. Twenty four possible effects on workers extracted from literature were presented in the questionnaire for evaluation, using a Likert scale of 1-5 for determining the relative importance of these effects. On the Likert scales, $1,2,3,4$ and 5 represented very low, low, average, high and very high effects respectively. The preferences of the craftsmen among these effects were subjected to factor analysis. Factor analysis involves decomposing a complex scattered and ungrouped problem into a multilevel heiractical structure of characteristics and criteria. The factor analysis results in data reduction, removal of duplication from a set of correlated variables and represents correlated variables with a smaller set of derived variables and the derived variables are relatively independent of one another.

The AHP approach involves decomposing a complex problem into a multilevel heirachical structure of characteristics and criteria, these criteria are simply such as those used in a Likert ranking types of variables. The process of data collection for the AHP involves pair wise judgments/evaluation of the criteria by the judging panel (Project managers in this case). Some of the advantages of the AHP includes:

- AHP can accommodate subjective and objective data very well (Islam, 2005)

- AHP compares two decision elements (criteria/alternative) at a time. In this way the decision maker becomes more focused and consequently the accuracy and reliability of the results are improved. As Chan and Lynn (1991) wrote: The use of the AHP for multi criteria rating is superior to other multiple attribute scoring models or to ad hoc weighing because it has the advantage of forcing the decision marker to focus exclusively on two objects at a time and the way they relate to each other, which is simpler and more manageable process than comparing five, twelve objects simultaneously.

\section{The AHP measuring scale}

AHP uses pair wise comparison of alternatives or variables (Saaty, 1990). This requires the decision marker to express their opinion about the value of a single pair wise comparison at a time using what Saaty (2001) called a fundamental scale (Table 1). The fundamental scale is a one to one mapping between the set of discrete linguistic choices available to the decision maker and a discrete set of numbers which quantify the linguistic choices (Oladapo 2011).

In comparing criterion A to criterion $B$, a decision maker may determine from 


\begin{tabular}{|c|c|}
$\begin{array}{c}\text { Intensity of } \\
\text { importance }\end{array}$ & Definition \\
\hline 1 & Equal importance \\
\hline 2 & Weak \\
\hline 3 & Moderate importance \\
\hline 4 & Moderate plus \\
\hline 5 & Strong importance \\
\hline 6 & Strong plus \\
\hline 7 & Very strong or demonstrated \\
\hline & importance \\
\hline 8 & Very, very strong \\
\hline & \\
\hline
\end{tabular}

\begin{tabular}{|c|c|}
\hline \begin{tabular}{|l|} 
Job Enrichment Types \\
Total quality management
\end{tabular} & Code \\
\hline Task rotation & TQM \\
\hline Work rest cycle /break & TR \\
\hline Combined task & WR \\
\hline
\end{tabular}

Table 2. AHP Task Based Job Enrichment Schemes

\begin{tabular}{|c|c|}
\hline Job Enrichment Types & Code \\
\hline Increase decision making opportunity for workers & ID \\
\hline Training programme & TP \\
\hline Self managed gang & SMG \\
\hline Workers participation in site meetings & WP \\
\hline
\end{tabular}

Table 3. Participation Based Enrichment Schemes 
the scale in table 1 that $A$ is of "very strong" importance than $B$ and accordingly assign a relative importance value of 8 to $A$. This measures that the value of the relative importance of $B$ to $A$ is $1 / 8$. The quantified judgments on pairs of criteria c in cj (pair wise comparisons) are presented by an $\mathrm{n} \times \mathrm{n}$ matrix.

$A=1,2,3 \ldots . h$. (1)

The entries ay are defined by the following entry rules.

Rule 1, if $a y=a$, then $a \mu=1 / a, a \neq 0$ Rule 2, If $\mathrm{Ci}$ is judged to be of equal relative importance to $\mathrm{Cj}$, then $a y=a \mu=1$, $=1$ for all $i$

Thus the matrix A has the form:

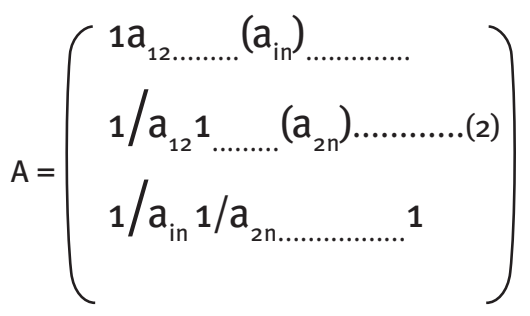

Where ay is the relative importance of criterion to criterion, having recorded the quantified judgments of comparisons on pairs $(\mathrm{Ci}, \mathrm{Cj})$ as numerical entries ay in the matrix $A$.

To find the weight of each criterion included in the ranking analysis, the eigenvector corresponding to the maximum eigenvalue is determined from matrix analyses. The principal eigenvector is computed and normalized to give the vector of weight.

\section{Data Analysis and Discussion of Findings}

Performance of Job Enrichment

Schemes used in the Construction Industry

In order to evaluate the relative performance of the eight job enrichment schemes considered in this research they were grouped into two homogeneous classes in order to facilitate an easier AHP process. The groups and the codes of the types of job enrichment schemes are contained in Tables 2 and 3.
The AHP was conducted for each group separately with the same group of respondents. To conduct the AHP for the task based group, the four job enrichment schemes were presented to the judging panel to conduct a pair wise comparison of their performances against one another based on the scale of evaluation in Table 1. The judgment of the project managers were used to generate a $4 \times 4$ matrix according to equation (2). Further matrix analysis including transposition and normalization were conducted to reduce the matrix to eigenvectors which are the relative rankings of the job enrichment schemes. The processes are shown in the Tables 4, 5 and 6 below

The maximum principal eigenvector $=4.29$

Consistency index $(\mathrm{Cl})=0.096$ Consistency Ratio (CR) $=11 \%$, this is more than the $10 \%$ prescribed, but it is borderline acceptable (Kniaz, 2013). Thus establishing that the judgment of the respondents was consistent and acceptable.

Usually, after constructing the pair wise judgment matrices, the consistency ratio (CR) is calculated for each matrix to ascertain the consistency of the judgment. The CR is calculated using the following equations.

$\mathrm{N}$ is the maximum principal eigenvec-

$\mathrm{Cl}=\frac{\mathrm{N}-\mathrm{n}}{\mathrm{n}-1}$

tor, $\mathrm{n}$ is the size of matrix,

$\mathrm{RI}=$ Random Consistency $\mathrm{CR}=\frac{\mathrm{Cl}}{\mathrm{RI}}$

Index as determined in table of Random consistency Index (Table 7) developed by Satty (2001).

\section{Performance of job enrichment schemes}

Table 8 contains the overall rankings of all types of job enrichment schemes and ratings within the task and participating based groups. In the overall rankings, increased decision making opportunity for workers ranked the highest with priority vector (PV) of 0.4125 . TQM, ranked next in importance to this with PV of 0.4045 . Other prominent job enrichment schemes are training programme, task rotation, work rest cycle and self managed gangs. They have priority vectors of $0.3164,0.2735,0.2168$ and 0.1675 respectively. In addition, the performance ranking within the two sub groups were considered. In the task based group, TQM ranked highest, next in importance to TQM were task rotation, work rest cycle and combined task. They have PV of $0.4045,0.2735$, 0.2168 and 0.1048 respectively. Also in the participation based group, the ranking of performance of the job enrichment schemes in order of importance was increased decision making opportunities for workers, training porgrammes, self managed gangs and workers participation at site meetings. They had PV of $0.4125,0.3164,0.1675$ and 0.1033 respectively.

\section{The effect of job enrichment schemes on construction workers}

Twenty four possible effects of job enrichment schemes were presented to the respondents to rate on a Likert scale of 1-5, representing very low effect to very high effects respectively. The data obtained was subjected to factor analysis. The appropriateness of the factor analysis for the factor extraction was determined by calculating the Kaiser Meyer Oikin (KMO) that measures the sampling accuracy and anti image correlation that determines the strength of relationship among the variables based on partial correlation coefficients. Bartlett's test of sphericity was also calculated. The Bartlett's test of sphericity tests the hypothesis that the correlation matrix is an identity matrix.

The value of the Bartett's test of sphericity was 518.979 , this was large compared with the associated significance level, $P=0.00$. This implied that 


\begin{tabular}{|c|c|c|c|c|}
\hline Job Enrichment Types & TQM & TR & WR \\
\hline TQM & 1 & 2.5329 & 2.0038 & 2.1966 \\
\hline TR & 0.3948 & 1 & 1.1509 & 2.4178 \\
\hline WR & 0.4991 & 0.8689 & 1 & 5.0150 \\
\hline CT & 0.4552 & 0.4136 & 0.1994 & 1 \\
\hline
\end{tabular}

Table 4. Pair wise comparison judgment matrix on Job Enrichment Types (Task based)

\begin{tabular}{|c|c|c|c|c|}
\hline Job enrichment types & TQM & TR & WR \\
\hline TQM & 0.4256 & 0.5259 & 0.4602 & 0.2066 \\
\hline TR & 0.1680 & 0.2076 & 0.2676 & 0.2274 \\
\hline WR & 0.2124 & 0.1804 & 0.2296 & 0.4718 \\
\hline CT & 0.1937 & 0.0858 & 0.0457 & 0.0940 \\
\hline
\end{tabular}

Table 5. Inconsistency matrix on Job Enrichment Types (Task Based)

\begin{tabular}{|c|c|c|}
\hline Enrichment types & Priority vectors & Rank \\
\hline TQM & 0.4045 & 1 \\
\hline Work rest cycle & 0.2168 & 3 \\
\hline Task rotation & 0.2735 & 2 \\
\hline Combined task & 0.1048 & 4 \\
\hline
\end{tabular}

Table 6. Priority vector (Normalized eigenvectors) on Job Enrichment Types (Task based)

the correlation matrix produced was an identity matrix. The value of the KMO statistic that measures sampling accuracy was 0.500 (Table 1 ). This figure was satisfactory for factor analysis (Cureton and D'Agostino, 1983). These results implied that factor analysis was appropriate for the factor extraction.

Furthermore, the extracted factors were subjected to principal component analysis and varimax orthogonal rotation. The results revealed that 17 of the 27 factors produced a factor solution with eigenvalue greater than
1. Explaining 62.821 percent. (Table 10) The loadings for each factor greater than 0.5 is shown in Table 11. The six principal factors of job enrichment affecting workers performance can be readily interpreted as follows:

- Factor 1: core job enrichment effects

- Factor 2: workers self actualization effects

- Factor 3: Peer surveillance effects

- Factor 4: workers dissatisfaction effects

- Factor 5: workers behavioural effects

Factor 6: Time effect
Core job enrichment effects comprises being a catalyst for highest level of performance (HLP), workers are happy, (WAH) increased job satisfaction (IJS), workers feeling in charge at work (WFC)and workers motivated (WM). Workers self actualization effects comprised workers fulfillment (WF), workers higher goals are achieved (WHG), and encouragement of manager - operative cooperation (MDC). Peer surveillance effects comprised peers monitoring one another (PMO) and minimized complaints from workers (MCW). Workers dissatisfaction effects included reduction of perceived conflicts between competing organizational goals (RPC) and increased fatigue due to intensification (JFI). behavioural effects included reduced absenteeism (RA), Rhythm interruption (RI) and reduced site wastage (RSW). Time effect included management of work time more effectively (MWT).

\section{Discussion of Findings}

- Factor 1: Core job enrichment effects The first factor interpreted as core job 


\begin{tabular}{|c|c|c|c|c|c|c|c|c|c|c|c|c|c|}
\hline Matrix size & 1 & 2 & 3 & 4 & 5 & 6 & 7 & 8 & 9 & 10 \\
\hline \\
\hline RI & 0.0 & 0.0 & 0.58 & 0.9 & 1.12 & 1.24 & 1.32 & 1.41 & 1.45 & 1.49 & 1.51 \\
\hline
\end{tabular}

Table 7. Random Consistency Index

\begin{tabular}{|c|c|c|c|}
\hline \multirow{2}{*}{ Job Enrichment types } & \multirow{2}{*}{ Priority vectors } & \multicolumn{2}{|c|}{ Rank } \\
\hline & & In class & Global \\
\hline TQM & .4045 & 1 & 2 \\
\hline Work rest cycle/break & .2168 & 3 & 5 \\
\hline Task rotation & .2735 & 2 & 4 \\
\hline Combined task & .1048 & 4 & 7 \\
\hline $\begin{array}{l}\text { Increased decision making } \\
\text { opportunity for workers }\end{array}$ & .4125 & 1 & 1 \\
\hline Training programme & .3164 & 2 & 3 \\
\hline Self managed gangs & .1675 & 3 & 6 \\
\hline $\begin{array}{c}\text { Workers participation in } \\
\text { site meetings }\end{array}$ & .1033 & 4 & 8 \\
\hline
\end{tabular}

Table 8. Priority vector (Normalized eigenvector) for all types of job enrichment schemes

\begin{tabular}{|c|c|}
\hline \begin{tabular}{|c|} 
Kaiser-Meyer-Oikin Measure of Sampling Accuracy \\
Bartlett's Test of Sphericity, Approx. Chi square
\end{tabular} & 0.500 \\
\hline Df & 518.979 \\
\hline Sig. & 300 \\
\hline
\end{tabular}

Table 9. KMO and Barlett's test

enrichment effect comprised of highest level performance, increased job satisfaction, motivated workers, workers are happy and workers feeling in charge of work. This factor represented $\mathbf{2 2 . 9} \%$ of the variance explained. This showed that it has a high significance as an effect of job enrichment on workers performance. The main characteristics of this factor is that it shows the basic features of an enriched job, namely, autonomy, that is, workers feel in charge at work, motivation, job satisfaction and happiness. Also from the organsation's view point, an enriched job should not merely make workers happy and fulfilled, but should also increase productivity and profitability of a company. This first factor gave the highest level of performance which is synonymous with higher level of productivity.

- Factor 2: Workers' self actualization effects

Workers self actualization effects comprised sub components such as workers are fulfilled, achievement of higher goals and manager - operatives cooperation. The factor represented $11 \%$ of the variance explained which shows its high significance. This extent of importance owes to the fact that self actualization concerns are the basic objectives of an enrichment programme. Being drawn from the top of Maslow's hierarchy of needs, it represents the highest level of managerial motivational accomplishment.

Factor 3: Peer surveillance effects Peer surveillance effects comprised peers monitoring one another and 


\begin{tabular}{|c|c|c|c|}
\hline Factor & Total & Percentage of variance & Cumulative percentage \\
\hline Factor 1: Core job enrichment effects & $5 \cdot 727$ & 22.907 & 22.907 \\
\hline $\begin{array}{l}\text { Factor 2: workers self actualization } \\
\text { effects }\end{array}$ & 2.783 & 11.131 & 34.039 \\
\hline Factor 3: Peer surveillance effects & 2.219 & 8.877 & 42.916 \\
\hline $\begin{array}{l}\text { Factor 4: workers dissatisfaction } \\
\text { effects }\end{array}$ & 2.029 & 8.115 & 51.031 \\
\hline Factor 5: workers behavioural effects & 1.513 & 6.052 & 57.083 \\
\hline Factor 6: Time effects & 1.434 & $5 \cdot 738$ & 62.821 \\
\hline
\end{tabular}

Table 10. Total variance explained

minimized complaints from workers representing $8.87 \%$ of the variance explained. As noted by (Delbridge et al, 1992), enrichment techniques such as TQM and quality cycles create incentives for peer surveillance, which basically lowers job satisfaction. But as it has shown in this study, peer surveillance can consequently result in minimal complaints from workers to the managers. This is because peer monitoring causes workers to first self correct themselves before reporting to management.

Factor 4: Workers' dissatisfaction effects

This comprised reduction of perceived conflict between competing organization goals such as safety and productivity, increased fatigue due to intensification. This represented $8.9 \%$ of the variance explained and a high significance. The significance is consistent with Herzberg's two factor theory which classified these category of factors as hygiene, whose presence must be maintained and ingrained in the job, otherwise their absence leads to dissatisfaction.

Factor 5: Behavioural effects Specific factors under this heading are reduced absenteeism, rhythm interruption, reduction of site waste and reduction of fatigue depending on individual workers morphological, physiological and ethical traits. These and other subjective factors of behavior and feelings have constituted great challenges of grasping human behavior in motivation researches.

\section{$>$ Factor 6: Time effects}

This comprised effective management of work time and reduction of supervision time. It represented $5.7 \%$ of the variance explained. Time management effectiveness is the hallmark of construction management and project management and a cardinal indicator of project delivery outcomes, hence its significance.

\section{Conclusion:}

The findings of this research signified that application of job enrichment as an incentive for construction workers has tremendous positive effects; these include core job enrichment effects, workers self actualization effects, peer surveillance effects, workers dissatisfaction effects, workers behavioural effects and positive time effects. These findings corroborated earlier claims of its efficacy based on its use in other climes; as shown by Kotila, (2001); its use led to five positive job outcomes; internal work motivation, job satisfaction, growth satisfaction, low absenteeism and high quality performance. The experiment reported by Mione (2006) had also espoused the use of job enrichment schemes and presented many benefits derived from the same.

However, the challenge of applying job enrichment in the construction industry is the lukewarm attitude of the industry to it and the concurrent need of domesticating the job enrichment that will be best suited to the peculiarities of the construction industry.

\section{References:}

Aina, 0. O. (2000) The effect of incentive schemes on construction productivity in Nigeria. M.Sc. Thesis, Department of Building, Obafemi Awolowo University, Ile Ife, Nigeria

Akindele, O. A. (2003) craftsmen and labour productivity in the Swaziland construction industry CIDB Postgraduate conference University of Witwatersrand, Port Elizabeth, South Africa.

Akrani, G. (2011) what is job enrichment! Meaning, features and advantages. www.kaylan-city.blogspot.com

Ameh, O. J. and Shokunbi B. B. (2013) Effectiveness of non-financial motivational scheme on construction workers output in Nigeria. Ethiopian Journal of Environmental Studies and Management, Vol. 6, No. 3. Pp 263-272. 


\begin{tabular}{|c|c|c|c|c|c|c|}
\hline Variables & Factor 1 & Factor 2 & Factor 3 & Factor 4 & Factor 5 & Factor 6 \\
\hline HLP & 0.723 & & & & & \\
\hline WAH & 0.714 & & & & & \\
\hline IJS & 0.708 & & & & & \\
\hline WPG & 0.690 & & & & & \\
\hline WM & 0.650 & & & & & \\
\hline WF & & 0.800 & & & & \\
\hline WHG & & 0.717 & & & & \\
\hline MOC & & 0.562 & & & & \\
\hline PMO & & & 0.817 & & & \\
\hline MCW & & & 0.713 & & & \\
\hline RPC & & & & 0.834 & & \\
\hline IFI & & & & 0.600 & & \\
\hline RA & & & & & 0.818 & \\
\hline $\mathrm{RI}$ & & & & & 0.658 & \\
\hline RSW & & & & & 0.566 & \\
\hline MWT & & & & & & 0.873 \\
\hline
\end{tabular}

Table 11. Loading of rotated factors

Aswathappa, K. (2005) Human resource and personnel management: McGrawhill, London.

Barcherding J. D. and Oglesby, C. H. (1974) Construction Productivity and job satisfaction, Journal of Construction Division ASCE Vol. 102, No. 4, pp 599-614.

Chan, Y. L. and B. F. Lynn, (1991). Performance Evaluation and the Analytical Hierarchical Process. Journal of Management and Accounting Research. (3). 57-87

Cureton, E. E. and R. B. D’Agostino (1983) Factor Analysis: An Applied Approach. Hillsdale, New Jersey.

Delbridge Rick, Turnbull Peter and Wilkinson Barry (1992) 'Pushing back the Frontiers: Management control and work intensification under JIT/TQM factory regimes' New Technology, Work and Employment 7(2): 97-106

Doloi, H. (2007) Twinning Motivation productivity and management strategy in construction projects. Engineering management journal.5(3) 55-63

Fagbenle O.I. (2000) The Impact of NonFinancial Incentives on Construction productivity. M.Sc. Thesis, Obafemi
Awolowo University, Ile-Ife

Hackman, J. R and Oldham, G. R. (1976) Motivation through the design of work: test of a theory. Organizational behaviour and Human Performance, Vol. 16, No. 2 pp. 250-279.

Hazeltine, C. S. (1976) Motivation of construction workers. Journal of the Construction Division ASCE, Vol. 102,. No. 3 , pp $477-510$.

Islam, R (2001) Employee Performance Evaluation by AHP: A Case Study. diSAHP 2005, Honolulu, Hawaii, July 8-10, 2005

Kniaz, k. (2013) Analytical Hierarchical Process. Net. Available at www. Kniaz.net/ software/A

Kotila, O. (2001) Job enrichment www. academia.emporia.edu/smithnil

Leach, D. and Wall, T. (2004) what is job design. Retrieved from www.shef.ac.uk.

Maloney, W. F. (1997) Strategic planning for Human resources management in construction. Journal of management in engineering ASCE Vol. 13, No. 3, pp 49-56.

Mione, P. (2006) Job enrichment www.edweb. sdsu.edu/people
Oladapo, A. A. (2011) Multi-criteria contractor selection - a practical application of analytic hierarchy process. Proceedingsinstitution of Civil Engineers Management Procurement and Law; 164, 2; 79-88

Ruthankoon, R. and Ogunlana S. O. (2003) Testing Herzberg's two factor theory in the Thai construction industry. Engineering, Construction and Management (ECAM). Emerald Insight Vol. 10. 5 pp 333 - 341.

Saaty, T. L. (2001) Decision Making for Leaders. The Analytic Hierarchy Process for Decision Making in a Complex World. RWS Publications Pittsburgh.

Saaty, T. L. (1990) How to make a Decision: The Analytical Hierarchy Process. European Journal of Operations Research. 48 (1990): 9-26

World Bank (2009), World Fact Book, UN Transparency International, Washington DC 